\title{
Impact of distributed meteorological forcing on snow dynamic and induced water fluxes over a mid-elevation alpine micro-scale catchment
}

Aniket Gupta ${ }^{1}$, Alix Reverdy ${ }^{1}$, Jean-Martial Cohard ${ }^{1}$, Didier Voisin ${ }^{1}$, Basile Hector ${ }^{1}$, Marc Descloitres ${ }^{1}$, Jean-Pierre Vandervaere ${ }^{1}$, Catherine Coulaud ${ }^{1}$, Romain Biron ${ }^{1}$, Lucie Liger ${ }^{2}$, Jean-Gabriel Valay ${ }^{2}$, and Reed Maxwell ${ }^{3}$

${ }^{1}$ Institute of Geosciences and Environment, University of Grenoble Alpes, Grenoble, France

${ }^{2}$ Station Alpine Joseph Fourier, University of Grenoble Alpes, Grenoble, France

${ }^{3}$ Department of Civil and Environmental Engineering, Princeton University, Princeton, NJ, USA

Correspondence: Aniket Gupta (aniket.gupta@univ-grenoble-alpes.fr) 
Abstract. From the micro to mesoscale, water and energy budgets of mountainous catchments are largely driven by topographic features such as terrain orientation, slope, steepness, elevation together with associated meteorological forcings such as precipitation, solar radiation and wind. This impact the snow deposition, melting and transport, which further impact the overall water cycle. However, this microscale variability is not well represented in Earth System Models due to coarse resolutions, and impacts of such resolution assumptions on simulated water and energy budget lack quantification. This study aims at exploring these effects on a 15.28 ha small mid-elevation (2000-2200 m) alpine catchment at Col du Lautaret (France). This grass-dominated catchment remains covered with snow for 5 to 6 months per year. The surface-subsurface coupled hyperresolution $(10 \mathrm{~m})$ distributed hydrological model ParFLOW-CLM is used to simulate the impacts of meteorological variability at spatio-temporal micro-scale on the water cycle. These include 3D simulations with spatially distributed forcing of precipitation, solar radiation and wind compared to 3D simulations with non-distributed forcing simulation. Our precipitation distribution method encapsulates the spatial snow distribution along with snow transport. The model simulates the snow cover dynamics and spatial variability through the CLM energy balance module and under the different combinations of distributed forcing. The resulting subsurface and surface water transfers are solved by the ParFLOW module. Distributed forcing induce a snowpack with a more spatially heterogeneous thickness, which becomes patchy during the melt season and shows a good agreement with the remote sensing images. This asynchronous melting results in a longer melting period and smoother hydrological response than the non-distributed forcing, which does not generate any patchiness. Amongst the tested distributed meteorological forcing that impacts the hydrology, precipitation distribution, including snow transportation, is the most important. Solar insolation distribution has an important impact in reducing evapotranspiration depending on the slope orientation. For the studied catchment mainly facing east, it adds small differential melting effect. Wind distribution in the energy budget calculation has a more complicated impact on our catchment as it participate to accelerate the melting when meteorological conditions are favourable but does not generate patchiness at the end in our test case.

\section{Introduction}

Mountains are natural water reservoirs, which mitigate seasonal precipitation variability through snowpack accumulation, whose progressive melting helps meet the fresh water and energy demand all year long. Climate projections for warmer climate in the near and far future for these regions will impact this mitigation process. Earth System Models (ESMs) are then challenged to simulate water fluxes in mountainous catchments where highly variable topographic features and vegetation, soils and geological structures affect water transfers at different scales. In particular topography controls snow/rain precipitation estimation and partition uncertainties, snow redistribution, slope/aspect effect and hill-shading that leads to spatial differential melting (Costa et al., 2020; Fang and Pomeroy, 2020; Pomeroy et al., 2003, 2007). Fan et al. (2019) argued that variable topography and catchment aspect can change the catchment hydrology and vegetation dynamics from steep to gentle slope, and from north to south aspect. Therefore, water budget modelling in the mountains is challenging, and the impacts of spatial heterogeneity, like snow depth distribution, ask for specific attention (Blöschl et al., 2019). 
Land surface models (LSMs) are an imperative component of the ESMs to capture exchanges of mass, energy and biogeochemical variables between the Earth surface and the atmosphere (Hurrell et al., 2013; van den Hurk et al., 2011). However, hydrology in LSMs is often poorly constrained. Major drawbacks include free draining subsurface hydrology and coarse resolution with no specific subgrid parameterization that could include slope and aspects features (as hillshading) or meteorological subgrid variability (Clark et al., 2015; Fan et al., 2019) or underground horizontal water redistribution (Tran et al., 2020). The spatial variability of hydrological processes and associated flux variable responses are generally too fine to be represented in LSMs when used at several $\mathrm{km}^{2}$ resolutions (Song et al., 2020). Bertoldi et al. (2014) mentioned that due to lack of detailed subsurface characterization, they failed to simulate the proper soil moisture, especially over sloppy terrains at $20 \mathrm{~m}$ resolution. Similarly, another study acknowledged that precipitation, solar insolation and wind distribution to hillslope catchment can simulate the spatial variability in hydrological fluxes including snow dynamics (Sun et al., 2018). Overall, the under representation of subgrid processes within mountain catchment limits the spatio-temporal snow coverage, differential melting and resulting streamflow responses.

The differential snow melting in mid-elevation catchment leads to variable saturation and pressure response which affects streamflow at the outlet. Loritz et al. (2021) mentioned the importance of the distribution of rainfall data over the catchment for spatial representation of surface and subsurface fluxes. The same study also highlighted that in a snowy catchment along with the runoff, the calibration of the hydrological models should also consider the surface dynamics of snow. Furthermore, evaluating the impact of snow redistribution by the wind over a catchment is challenging because it involves the hyper-resolution of wind vector $(1 \mathrm{~m}$ to $100 \mathrm{~m}$ ) to catch the snow transportation in a mountainous catchment (Marsh et al., 2020; Pomeroy and $\mathrm{Li}, 2000$ ). Liston et al. (2016) showed the relevance of the physical-statistical distribution of wind field in capturing the snow dynamics. Similarly, shortwave plays a significant role from a climatic, hydrologic and biogeochemistry point of view. Nijssen and Lettenmaier (1999) mentioned that shortwave affects the majority of exchanges between land and the atmosphere. Land surface - radiation interactions rely on directional effects and are often neglected in the models. Sampaio et al. (2021) highlighted that the daily/diurnal cycles of heat are also dependent on the surface orientation but merely taken into account in hydrological modeling. However, individual meteorological distribution sometimes are not enough to capture the real catchment behaviour. Combining the terrain-based distribution of precipitation data with solar radiation and wind distribution helps capturing differential melting along the slope, including distribution and redistribution of snow in the catchment (Sun et al., 2018). However, these diverse approaches in hydrological modeling are still limited and merely account for all prominent physical processes.

Most of the monitoring in mountainous catchment areas merely exceeds from one to two meteorological stations (Meerveld et al., 2008; Revuelto et al., 2017; Song et al., 2020). It raises complexity in setting the hyper-resolution distributed modeling. However, there are proven statistical methods available for distributing the meteorological parameters along the catchment (Liston and Elder, 2006). Many studies focus only on temperature distribution through model input to catch the spatial variability of snow-dominated fluxes in hillslope catchment (Aguayo et al., 2020; Fang and Pomeroy, 2020). However, these model resolutions remain too coarse to simulate the micro-scale hydrological behaviour. Moreover, only few studies on snowpack simulation have used hyper-resolution distributed forcing (Günther et al., 2019; Baba et al., 2019; Vionnet et al., 2012). These 
studies highlighted the importance of meteorological distribution and need of hyper-resolution modeling framework. Still, practices for distributing multiple meteorological-forcing in hyper-resolution hydrological modeling of mountainous catchments is limited.

In order to overcome those LSMs limitations and quantify the impacts of fine scale variability on water budget, we studied the impact of spatial distribution of precipitation, wind and shortwave radiation on the hydrological budget in a unique modelling exercise using a small-scale alpine mid-elevation (2000-2200 m) catchment (15.28 ha) that can be investigated in details regarding surface and subsurface conditions. We have used a hyper resolution subsurface hydrological model (ParFLOW) coupled with the Community Land Model (CLM) at $10 \mathrm{~m}$ resolution to simulate the hydrological fluxes and spatio-temporal snow cover dynamics. From the perspective of hillslope hydrology we addressed the following points:

- Ability of the hyper-resolution modeling using 3D critical zone model ParFLOW-CLM to capture the water/energy fluxes in a sub-alpine snow-dominated catchment.

- Impact of individual and combined distribution of precipitation, solar radiation and wind; and response in simulating the catchment dynamics.

- Snow cover spatio-temporal dynamics in a micro-scale catchment and its role in controlling the water budget.

From onward, the second section presents the study area location and its characteristics. The third section covers the methodology with details about the modeling framework. This section also includes detail about the meteorological distribution. Fourth section details the domain discretization and model setup. The fifth and sixth sections present the results/discussion and conclusion, respectively.

\section{Study Area}

\subsection{Geography and geology}

The study area lies in a mid-elevation range of sub-alpine region in the French Alps, close to the mountain pass, Col du Lautaret (Fig. 1). Being a micro-scale catchment, it covers 15.28 ha with elevation ranging between 2000 and $2200 \mathrm{~m}$. It consists of steep slopes facing East in the upper area, and a wetland lies in the lower area. The catchment is covered by snow for a period of 5 to 6 months in average. The $\mathrm{C} 4$ grassland dominates the summer with $5 \%$ woody coverage that includes some larches, alders and bushes. Flux'Alp meteorological station lies just adjacent to the catchment (Fig. 1) in a flat zone. Over the catchment, soil depths range from $20 \mathrm{~cm}$ on steep slopes to more than $2 \mathrm{~m}$ on flat wetlands. Soils are rich in clay with high porosity and retention capacity. This rich clay soil slowly transits to the hard rock towards the regolith up to $5 \mathrm{~m}$ at the deepest locations. The base rock is highly fractured and made of "Flysch des Aiguilles d'Arves", a shale-sandstone alternation, with bedding slopes ranging from sub-horizontal to sub-vertical (https://infoterre.brgm.fr/). 
(a)

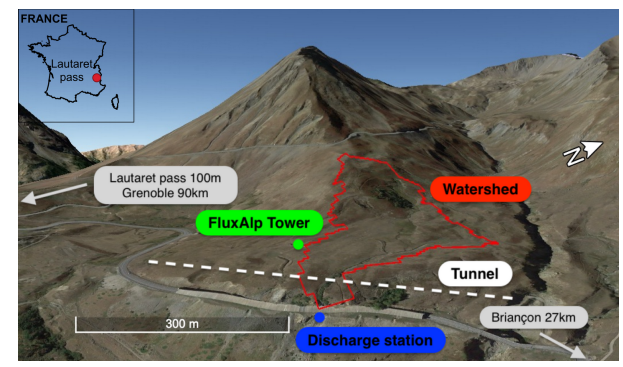

(b)

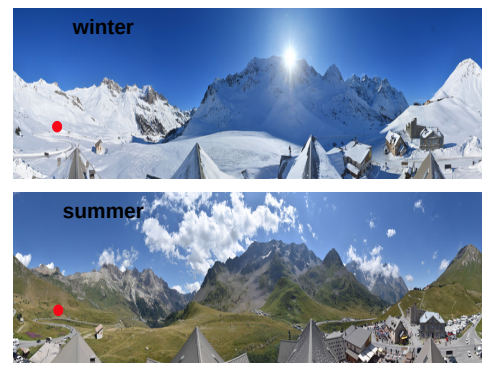

968400

968550

(c)

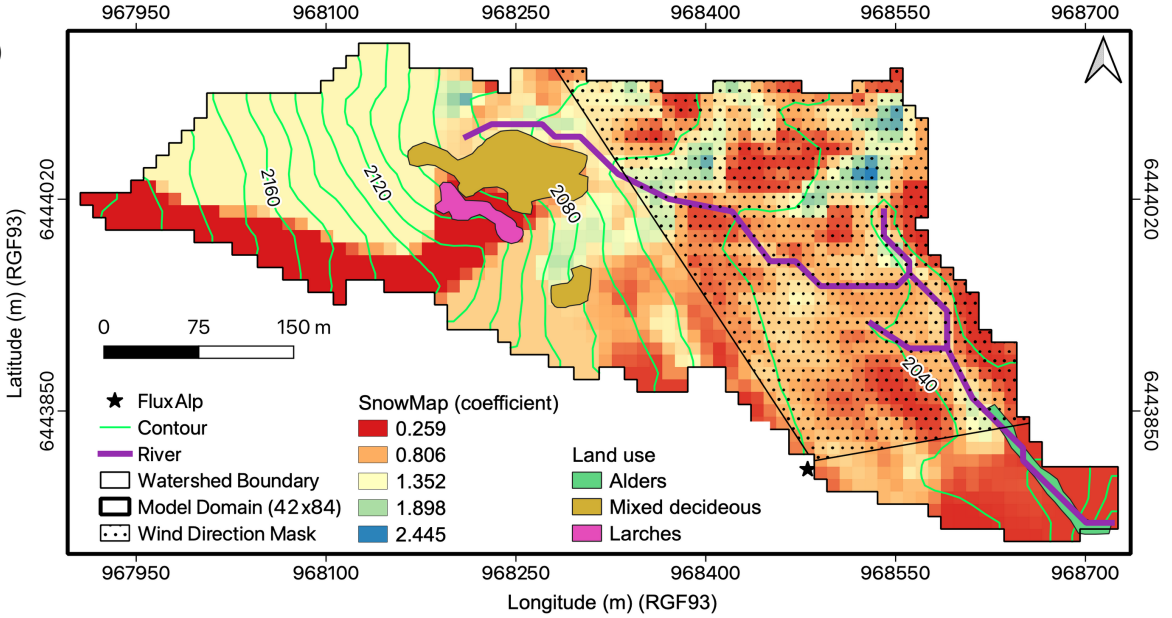

Figure 1. (a) overview of the study area at Col du Lataret, France, the small sub-alpine catchment is delineated in red with the outlet at the blue point. Green dot is the Flux-alp micro-meteorological station. (b) landscape views of the Lautare pass area in winter (January) and summer (July). (c) Catchment domain ( $84 \times 42$ grid cells at 10m resolution) with river branches (violet), elevation contours (green) and tree patches. Coloured pixels represent the distributed snow coefficients. The dotted area is the approximated footprint for the for daily spring wind directions.

\subsection{Climate}

The study area is a typical mid-latitude alpine environment. Figure 2 shows the meteorological observation for the simulated hydrological year starting the 11 November 2017 at the first snowy day to 10 November 2018. The catchment has a long winter season with 5 to 6 months of snowfall (Fig. 2a) and a complete snow cover. Flux'Alp meteorological station records a total of $1530 \mathrm{~mm}$ year-1 precipitation, out of which $970 \mathrm{~mm}$ was snow (dry) in the studied period. According to 2017-2018 weather data (simulation year for this study), the site-average temperature is $4{ }^{\circ} \mathrm{C}$. The site has below-zero winter conditions, with a -7.4 ${ }^{\circ} \mathrm{C}$ mean February temperature recorded and a $14{ }^{\circ} \mathrm{C}$ mean July temperature (Fig. 2b). Strong winds are common throughout the year, usually from the South-West direction along the mountain pass (Fig. $2 \mathrm{c}$ and $4 \mathrm{a}$ ). The temperature and specific humidity annual cycle are well phased (Fig. 2d). March is the most humid period of the year, while July is the driest. The studied catchment has significant differences between summer and winter solar radiation (Fig. 2f). Additionally, mountains around 
the catchment reduce the sunshine period with projected shadow, especially during winter. These observations also served as forcing to the model.
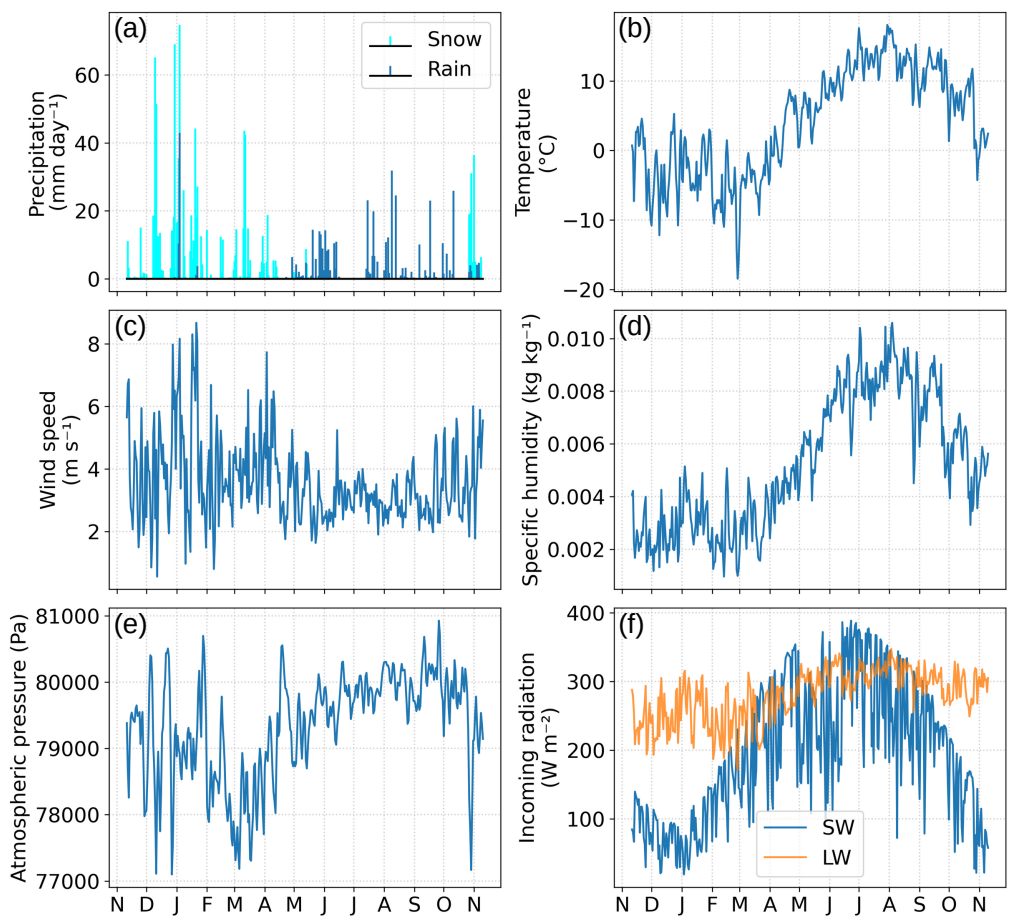

Figure 2. Daily meteorological observation at Col du Lautaret for hydrological year 2017-2018: precipitations (a), air temperature (b), wind speed (c), specific humidity (d), Atmospheric pressure (e) and short wave (SW) and long wave (LW) incoming radiations (f).

\subsection{Monitoring}

10 Most of the monitoring on the site has started in 2012. It includes the temperature and humidity (CS215, Campbell Sc.), atmospheric pressure (Setra CS100, Campbell Sc.), Wind speed and wind direction (Vector anemometer A100LK and W200P, Campbell Sc.), 4 components of net radiation (CNR4, Kipp and Zonen), snow height (SR50A, Campbell Sc.), and NDVI (Normalised Difference Vegetation Index) measured through Skye Instruments SKR1800. Since 2015, the site received eddy covariance sensors composed of the LI-COR LI-7200 close-path gas analyser and the HS50 Gill 3D sonic anemometer. Since 2017 the site has also add an OTT Pluvio rain gauge. Site setup, monitoring and data processing follows the ICOS (https://www.icosri.eu/) standards, and the site has entered this program since 2018. All measured variables are recorded at 15 min time step and then reduced to a $30 \mathrm{~min}$ time series for this study. The EddyPro Software is used to process the turbulent fluxes at the same 30 min time step following the ICOS recommendations (Hellström et al., 2016). 


\section{Methodology}

\subsection{ParFLOW-CLM (PF-CLM)}

In this study, we used ParFLOW-CLM, an integrated surface-subsurface coupled hydrological model, to simulate the impact of distributed meteorological forcing on the water transfers (Jones and Woodward, 2001; Ashby and Falgout, 1996; Kollet and Maxwell, 2006; Maxwell, 2013; Maxwell and Miller, 2005; Kollet and Maxwell, 2008). ParFLOW is a parallel integrated hydrological model optimised to solve the surface and subsurface flow. ParFLOW solves the three-dimensional Richards equation to calculate the water pressure field and transfers within unsaturated and saturated porous media (Jefferson and Maxwell, 2015). Relative permeability and soil retention curves are based on the Van Genuchten relationships (Van Genuchten, 1980). A multigrid-preconditioned conjugate gradient solver and the Newton-Krylov solver for non-linear equations (Kuffour et al., 2020) makes the model efficient to run on parallel computers. ParFLOW includes a terrain-following grid which eases boundary conditions prescription mesh refinements around numerically challenging interfaces such as the soil surface, and subsequent overland flow calculation. At the model surface any saturated cell flows according to the two-dimensional Kinematic wave equation (Kuffour et al., 2020). ParFLOW then maintains a continuous pressure head value from the bottom to the top of the domain and explicitly calculates fluxes between ground water and surface water. Infiltration excess (Horton, 1933) or saturation excess (Dunne, 1983) runoff are then generated according to Richards equations. Flow-routing uses the D4 scheme to determine the flow direction based on individual slopes in $\mathrm{x}$ and $\mathrm{y}$ direction and has been calculated according to Condon and Maxwell (2019). The CLM (community land model) is a land surface model designed to compute the land-water-energy exchange between the surface and atmosphere (Dai et al., 2003). CLM accounts for land cover, surface temperature, soil moisture, soil texture, soil colour, root depth, leaf and stem area, roughness length, displacement height, plant physiology and thermal and optical properties of medium to calculate the surface energy and water balance. It calculates evapotranspiration as the sum of evaporation, vegetation evaporation, transpiration and re-condensation. It also includes a five adaptive layer snow scheme to predict mass of water, mass of ice, layer thickness and temperature as main driving variables. CLM two-stream radiative transfer scheme accounts for direct and scattered radiation by snow in visible and near infrared wavelengths. In CLM, when pixels cover a large range of elevation, snow fraction is used to account for the surface uncovered by snow. In our study snow fraction was reduced to 0 (no-snow) or 1 (snow) values because our pixels are small enough $(10 \times 10 \mathrm{~m})$ that we consider their snow coverage to be uniform. Therefore, CLM can handle the spatial/temporal snow distribution, associated water fluxes (melting, sublimation, infiltration) and evaporative fluxes according to spatial/temporal heterogeneous surface conditions (Temperature, water/snow inputs, incoming radiations, wind and vegetation). After computing the surface exchanges like evaporation, transpiration, snowmelt and precipitation infiltration to and out of the soil, these are applied as source/sink in the Richards equations. A further note on ParFLOW terminology and the model capability is included in the user manual (https://github.com/parflow). 


\subsection{Meteorological distribution}

\subsubsection{Precipitation}

The precipitation data from the rain gauge have been first processed to account for the lack of gauge shield (Klok et al., 2001). The adopted algorithm follows as:

$P_{\text {corr }}\left(x_{0}, y_{0}\right)=P\left(x_{0}, y_{0}\right) *\left(a+b * u\left(x_{0}, y_{0}\right)\right)$

where, $P_{\text {corr }}$ is the corrected precipitation $(\mathrm{mm}), P$ is measured precipitation $(\mathrm{mm})$ at observation station, $u$ is the wind speed at observation station in $\mathrm{m} \mathrm{s}-1, a$ and $b$ are correction factors, and are different for rain $(a=1.04, b=0.04)$ and snow ( $a$ $=1.18, b=0.20)$.

To account for snow coverage spatial variability on the catchment domain, $S_{c}(x, y)$, the snow precipitation at $(x, y)$ location was calculated using a snow coefficient map $C_{s}(x, y)$ from the ratio between the measured snow height at the gauge to the snow height measured through the laser scan on the same day (21/02/2018) at the end of the accumulation period (Fig. 1). The snow height calculated from the laser is the difference of apparent snow height (from laser scan) at the end of the accumulation period and the digital elevation model (DEM) for the surface without snow. The snow DEM and surface DEM were prepared at the resolution of $2 \mathrm{~m}$ and were upscaled to $10 \mathrm{~m}$ resolution for modeling purpose. The $S_{c}(x, y)$ calculation hypothesizes that distributed snow cover on that date aggregates all spatial heterogeneity of the snow deposition including the snow transportation (redistribution). It also neglects the snow compaction between date of deposition and the laser scan. Then the corrected Snow precipitation is calculated according to:

$\left.S_{c}(x, y)=S_{m}\left(x_{0}, y_{0}\right) * C_{s}(x, y)\right)$

where, $S_{m}(x, y)$ is the measured snow precipitation at the observation station. Unfortunately, it can be noted that the laser scan didn't cover the upper part of the catchment. Zones not covered by the scan were each given a fixed value, according to our field observation. Moreover, due to micro-scale catchment and a low altitudinal range, elevation differences between upper and lower locations $(211 \mathrm{~m}$ ) have not been considered and the rain has not been distributed according to an altitudinal gradient.

\subsubsection{Shortwave radiation}

The shortwave radiation, $S W_{c}(x, y)$ has been distributed from the observed shortwave measurement, $S W_{m}\left(x_{0}, y_{0}\right)$ at the meteorological station considering the sun position and the terrain effect (Liston and Elder, 2006). Equation 3 partitions diffuse (30\%) and direct shortwave (70\%) contributions from the observed shortwave, and equation 4 accounts for the terrain features based on their orientation which is integrated as a solar cosine function in equation 3. The partition of diffuse and direct shortwave was taken from the CLM technical setup (Oleson et al., 2004).

$$
\begin{aligned}
& \left.S W_{c}(x, y)=(0.7 \operatorname{cosi}(x, y)+0.3) * S W_{m}\left(x_{0}, y_{0}\right)\right) \\
& \operatorname{cosi}(x, y)=\cos \beta(x, y) * \cos Z(x, y)+\sin \beta(x, y) * \sin Z(x, y) * \cos \left(\mu(x, y)-\xi_{s}(x, y)\right)
\end{aligned}
$$


$S W_{c}$ is the corrected shortwave $\left(W^{-2}\right)$ at a coordinate location, $S W_{m}$ is measured shortwave at the observation station, $i$ is the solar angle function of the slope angle $\beta$, the slope southern azimuth $\xi_{s}$, sun southern azimuth $\mu$ and solar zenith angle $Z$.

\subsubsection{Wind speed}

Wind speed were spatialized to better account for the estimation of turbulent fluxes (Liston and Elder, 2006). The wind speed was distributed as,

$W_{w}(x, y)=1+0.58 \Omega_{s}(x, y)+0.42 \Omega_{c}(x, y)$

$\Omega_{s}(x, y)=\beta(x, y) * \cos (\theta(x, y)-\xi(x, y))$

$\Omega_{c}(x, y)=0.25 \sum\left(Z(x, y)-0.5\left(Z_{i}(x, y)+Z_{j}(x, y)\right)\right) / d$

$W_{c}(x, y)=W_{w}(x, y) * W_{m}\left(x_{0}, y_{0}\right)$

where, $W_{w}$ is the wind weighting factor at a coordinate location as function of wind direction slope $\left(\Omega_{s}\right)$ and curvature $\left(\Omega_{c}\right)$, $i$ and $j$ are the search direction (N-S, E-W, NE-SW, SE-NW), $d$ is $2 \eta$ for cardinal axes and $2 \sqrt{2} \eta$ for others, $\eta$ is the search distance and, $Z$ is the elevation, $\beta$ is the slope angle, $\theta$ is the wind direction and $\xi$ is the slope azimuth. The search distance $d$ for curvature is set to $50 \mathrm{~m}$ (Revuelto et al., 2020). Finally, the wind weighting factor $\left(W_{w}\right)$ was multiplied with the wind measured $\left(\mathrm{ms}^{-1}\right)$ at observation station $\left(W_{m}\right)$ to obtain the terrain corrected wind $\left(W_{c}\right)$.

Along with precipitation, shortwave and wind there are three more forcing variables to the model which are the temperature, pressure and specific humidity. However, as the model was set to a micro-scale catchment with little altitudinal variability, we did not distribute these parameters over the catchment.

\section{Domain discretization and simulation setup}

The surface domain of 15.28 ha was discretized at a hyper-resolution of $10 \mathrm{~m}$ with the total number of $84 \times 42 \times 11$ (longitude $\times$ latitude $\times$ levels) pixels (Fig. 1) on a terrain following grid. As mentioned earlier, the model was mainly built and forced using the observations; hence, the input data either are observational data or secondary data derived from observation. These data include the temperature, precipitation, wind, short wave, humidity and pressure plotted on figure 2 . These observations data are available at 30 minutes interval from the instruments and few data are even available at a higher temporal resolution and upscaled to the 30 minutes temporal resolution. Leaf area index (LAI) and stem area index (SAI) were calculated from NDVI measurements. Displacement height (d) and roughness length (z0) were calculated from the vegetation height following Brutsaert rules (Brutsaert, 1982). Grass height was calculated from the snow height sensor during the summer months considering NDVI to identify the vegetation/snow periods. LiDAR Digital Surface Model (DSM) of $2 \mathrm{~m}$ resolution was available for the catchment and upscaled to $10 \mathrm{~m}$ resolution for various elevation related parametrization in the model. Upscaled DSM has been processed with PriorityFLOW to generate the slope maps in $\mathrm{x}$ and y direction (Condon and Maxwell, 2019). Landcover map was generated through field observations and satellite image while the Manning coefficients were assigned using the landcover 
map. Snowmelt dynamics were compared to Sentinel 2A and Sentinel 2B products from Sentinel satellite obtained through USGS Earth Explorer (https://earthexplorer.usgs.gov/).

The lateral and bottom boundary conditions were set to no flow and the surface boundary condition was an atmospheric pressure condition that allow surface runoff (Kollet and Maxwell, 2006). Hence, the inflow and outflow are restricted to exchange only through the surface. Subsurface has been made heterogeneous with three layers of soil, regolith and flysch divided into 11 numerical cells (Fig. 3). The bottom of the domain was set deep enough to accommodate various subsurface movement (118 $\mathrm{m}$ deep from the surface). The soil physical parameters used in this study includes porosity, permeability, soil horizons and Van Genuchten parameters. Soil horizons distribution were determined from an electromagnetic survey measuring apparent electrical conductivity (related to water and clay content) and ground penetrating radar (GPR) measuring soil thickness along key-profiles, while the soil properties were determined by field permeability experiments (Reynolds and Elrick, 1991; Vandervaere et al., 2000a, b) and laboratory mercury porosity experiments. Elaboration about the detailed hydro-geological characterization is beyond the scope of this study and will be detailed in a companion paper. This study is more focused on surface dynamics due to meteorological distribution.

(a)

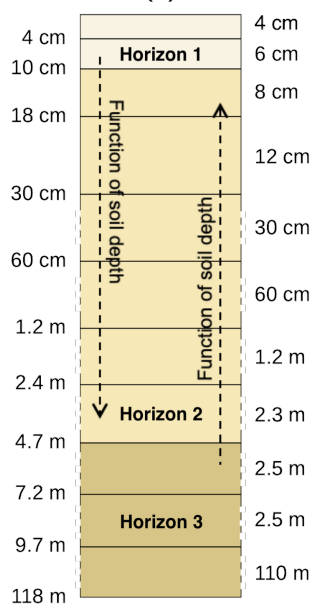

(b)
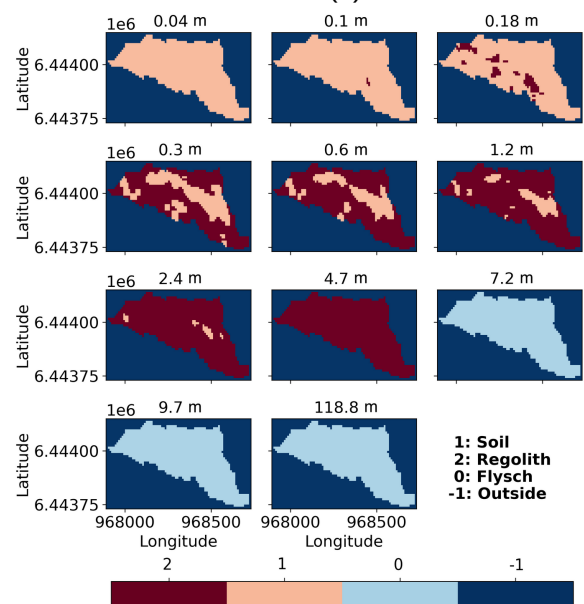

(c)

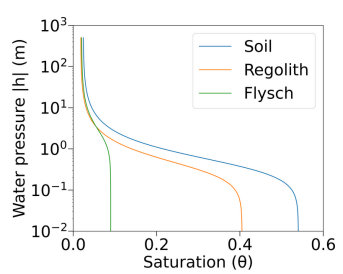

(d)

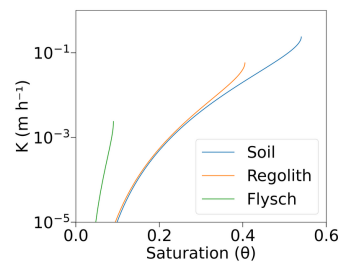

Figure 3. Subsurface configuration used for discretizing the domain. (a) The vertical distribution of subsurface layer with thickness (right) and depth (left) of each grid cell. (b) Spatial distribution of subsurface layer including soil (salmon), regolith (red) and flysch (blue). These layers vary in their hydro-geological parameters from conductivity, porosity to the soil transfer functions which are shown in (c- Soil retention curve) and (d- hydraulic conductivity curve).

The model results were outputted at hourly time-step. The Universal Time Zone (UTC) is considered in terms of monitoring and modeling for this study. Before running the simulations, a 10-years spin-up with 'SeepageFace' (no runoff) conditions performed to bring the model to a hydrological balance. The yearly subsurface stock difference is used as spin-up parameter which reached to equillibrium in the end of 10th year.

The different simulations setup for this study include: 
-1-dimensional column simulation with only precipitation distributed mean forcing (Pix-PM)

- 3-dimensional simulation with only precipitation distributed mean forcing (1D-PM)

- 3-dimensional simulation with all distributed mean forcing (1D-AM)

- 3-dimensional simulation with all distributed forcing (2D-AD)

- 3-dimensional simulation with only precipitation distributed forcing (2D-PD)

- 3-dimensional simulation with only shortwave distributed forcing (2D-SD)

- 3-dimensional simulation with only wind distributed forcing (2D-WD)

All 1D simulations means the simulations with non-distributed forcing. All simulations are forced with the same annual amount of precipitation $(1443.72 \mathrm{~mm})$, which corresponds to the spatial average of precipitation after applying the distribution formulae (eq. 2). It is reduced compared to what is measured at the rain gauge station (1531.96 mm) because the precipitation distribution process leads to a different average amount of snow over the catchment. Taking the average value make easier hydrological budget comparison between simulations. Similarly, shortwave radiation amount is not the same considering the measured value (averaged shortwave: $190.8 \mathrm{~W} \mathrm{~m}$-2) and the distributed one when taking into account the slope angles (152.1 W m-2). For this forcing we did several simulations to better analyse the results. Pix-PM, 1D-PM, 2D-PD and 2D-WD were run with the zenithal solar radiation observation (measured shortwave) directly from the radiation sensor, and 2D-AD and 2D-SD were run with distributed solar radiation according to equation 5-8 and the average of this distributed forcing for 1D-AM simulations. 1D-PM corresponds to a classical hydrological simulation for small catchment when one applies the meteorological forcing directly from a weather station nearby. The later four proposed simulations have been run to quantify the effect of spatially distributed forcing all together or individually. Meteorological distribution algorithms described above serves the purpose of catching the slope, curvature and aspect effect in spatial distribution. Even at a micro-scale, one can observe the spatial meteorological variability along the grid after applying equation 2-8 (Fig. 4). In wind distribution, there is not so much variation. The mean wind speed before and after the spatial distribution is $3.6 \mathrm{~m} / \mathrm{s}$ and $3.5 \mathrm{~m} / \mathrm{s}$, respectively.

\section{Results and Discussions}

\subsection{Non-distributed forcing simulation}

Figure 5a-b shows the catchment response from the 1D-PM for a full hydrological year and the monthly budgets for storage variation, surface and subsurface fluxes. It shows that the hydrological year begins with the accumulation period until the end of March. December and January are the snowiest months. Some snowmelt events (magenta line) can be observed during this period because of short above zero degree episodes (Fig. 2b) but generate very few runoff (black line). In April, continuous melting is simulated because of warmer positive temperature (Fig. 2b) but also rain on snow events. This produces the highest river discharge peaks on the hydrograph following the daily cycle (between min and max discharge values at daily timestep) and the rain timing (highest discharge peaks). This period also increases the subsurface stock (Fig. 5b) which produces a base flow that combines with the snowmelt contribution to streamflow. 
(a)

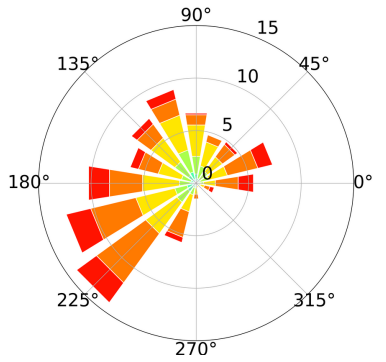

(c)

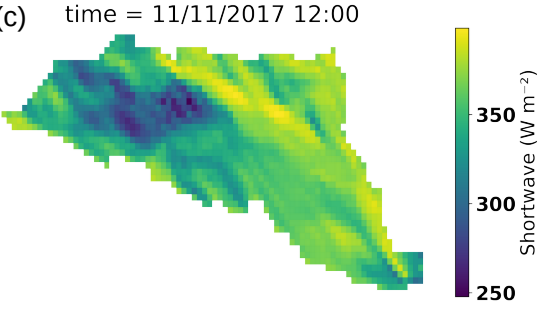

(b) $\quad$ time $=11 / 11 / 201717: 30$

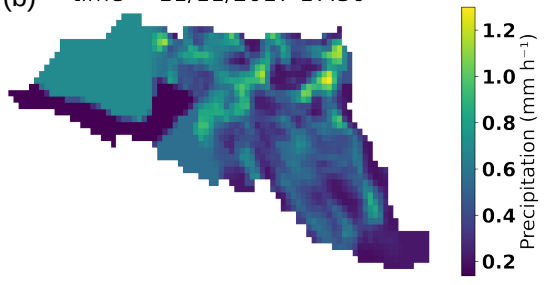

(d) $\quad$ time $=11 / 11 / 2017$ 17:30

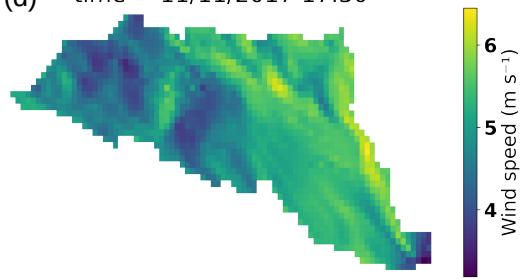

Figure 4. (a) Windrose diagram. (b) Precipitation distribution along the watershed. (c) Shortwave distribution along the watershed. (d) Wind distribution along the watershed. All are plotted for the 11/11/2017 at 5:30 pm and 12:00 pm for shortwave.

One of the most important and noticeable point using the non-distributed forcing is the sudden disappearance of the snow at the end of the snowmelt season, which is usually not observed on actual field observation. This means that all the pixels behaved the same way and there is no noticeable impact of the subsurface hydrology on the catchment spatial variability when considering a uniform forcing. From June to the beginning of the next snow period, summer rains produce almost instantaneous river responses and subsurface stock sustains stream discharge for several months. During this period, one can note a radical change of net radiation because of the change of the albedo from snow cover ( 0.8) to herbaceous ( 0.2) (see Fig. 9(a)). Earlier in spring net radiation contributes to snowmelt (the two variables are correlated) because of higher sun elevation more clear sky conditions and higher daily temperature.

During winter and spring monthly cumulated ET is very small (Fig 5b) because of low available energy and complete snow coverage. After the complete snowmelt the model simulates much higher monthly cumulated ET according to the prescribed LAI cycle. ET at this period is higher than the monthly cumulated rain (June, July, September), which means that ET participates to the extraction of shallow water storage during the summer. This can be seen by the difference of subsurface storage decline between the summer (higher water storage diminution) and the winter (lower water storage diminution). In October one can notice a small subsurface stock increment when ET reduces because of vegetation decay. At the end of the hydrological year, the subsurface water storage has a low negative value of $0.15 \mathrm{~mm}$ which is the hydrological unbalance much smaller than the annual cycle.

Figure 5c-d present the same time series and monthly water budgets for the 1D-AM simulation. The major difference is that precipitation, solar radiation and wind velocity have been prescribed using the spatial average of the distributed field. The major difference comes from solar radiation reduction from $190.8 \mathrm{~W} \mathrm{~m}-2$ to $152.1 \mathrm{~W} \mathrm{~m}-2$ on average, which reduces melting 

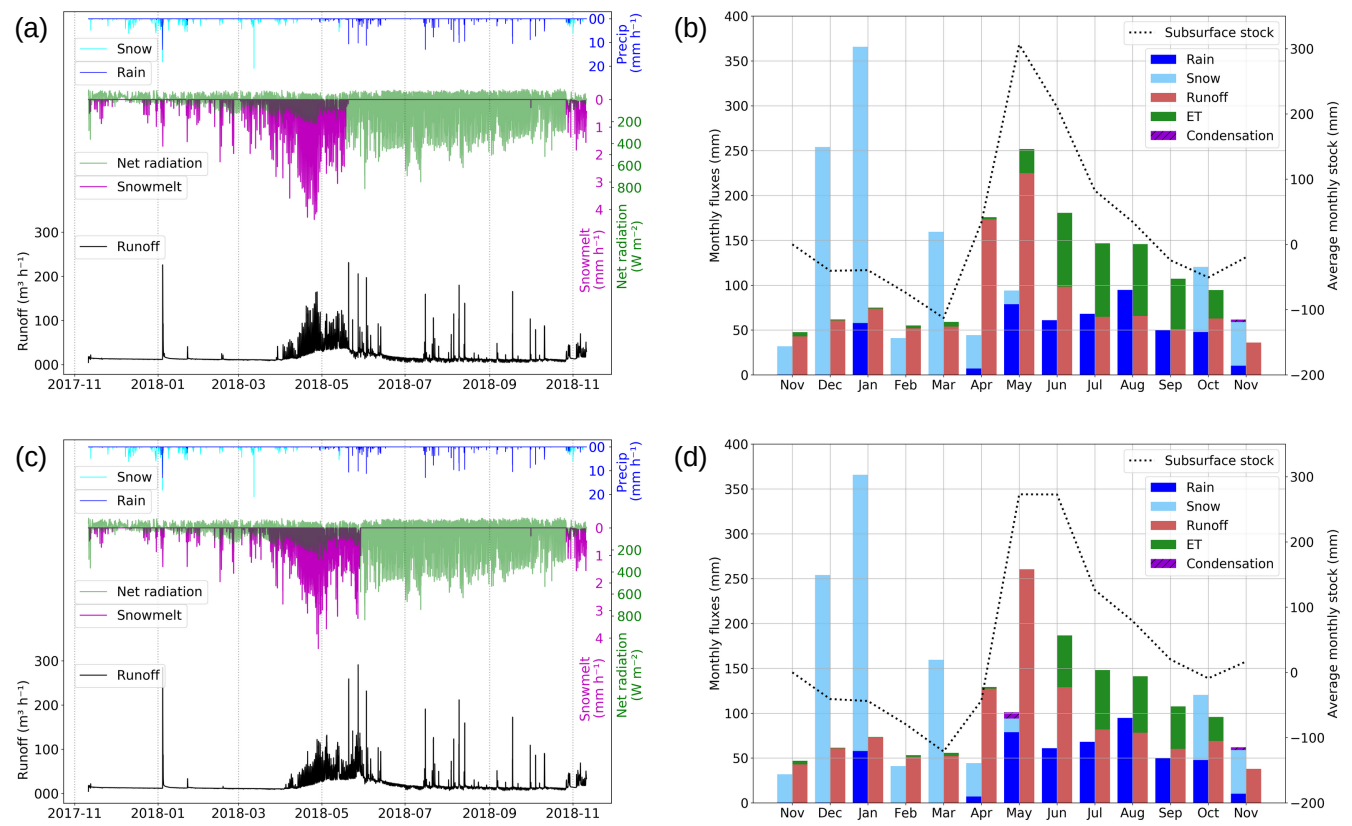

Figure 5. (a) Precipitation (rain - blue and snow - light skyblue), streamflow (black), snowmelt (magenta) and net radiation (green) regimes along the simulation period for only precipitation distributed mean simulation (1D-PM). (b) Monthly water budget for 1D-PM simulation including rain (blue) snow (light skyblue), Runoff (red), ET (green) and condensation (purple). Black dotted line is the total sub-surface water storage. (c)(d) same as (a) and (b) but for all distributed mean simulation (1D-AM).

and ET. It leads to a 9 days longer snow period, an increased runoff and an increased infiltration of $34.61 \mathrm{~mm}$ (Table 1). This unbalance vanishes after several years leading to higher water table and then higher runoff with a 0.8 runoff coefficient. This means that for similar geomorphology, any reduction in input solar radiation because of orientation or else will lead to higher water table and then higher runoff coefficient.

\subsection{Distributed forcing simulations}

In the following section, we will discuss the differences in surface fluxes for all combined and individually distributed simulations, along with their role in streamflow generation.

Looking at the surface fluxes on Fig. 6a, one can see that the simulation with all distributed forcing (2D-AD) have longer snowmelt period with a long steady decline during the streamflow recession till mid-July. Compared to the non-distributed forcing simulation 1D-PM, the distributed forcing is causing a smoother snowmelt dynamic which last till July and correspondingly impacts the net radiation recharge and streamflow discharge dynamic with significant differences for streamflow values during the core of the melting period up to $50 \%$ more for 1D-AM compared to 2D-AD. However, budget terms are pretty much the same between $1 \mathrm{D}-\mathrm{AM}$ and $2 \mathrm{D}-\mathrm{AD}$. From this point of view distribution at that scale seems not to add much information compared to a $1 \mathrm{D}$ forcing. 

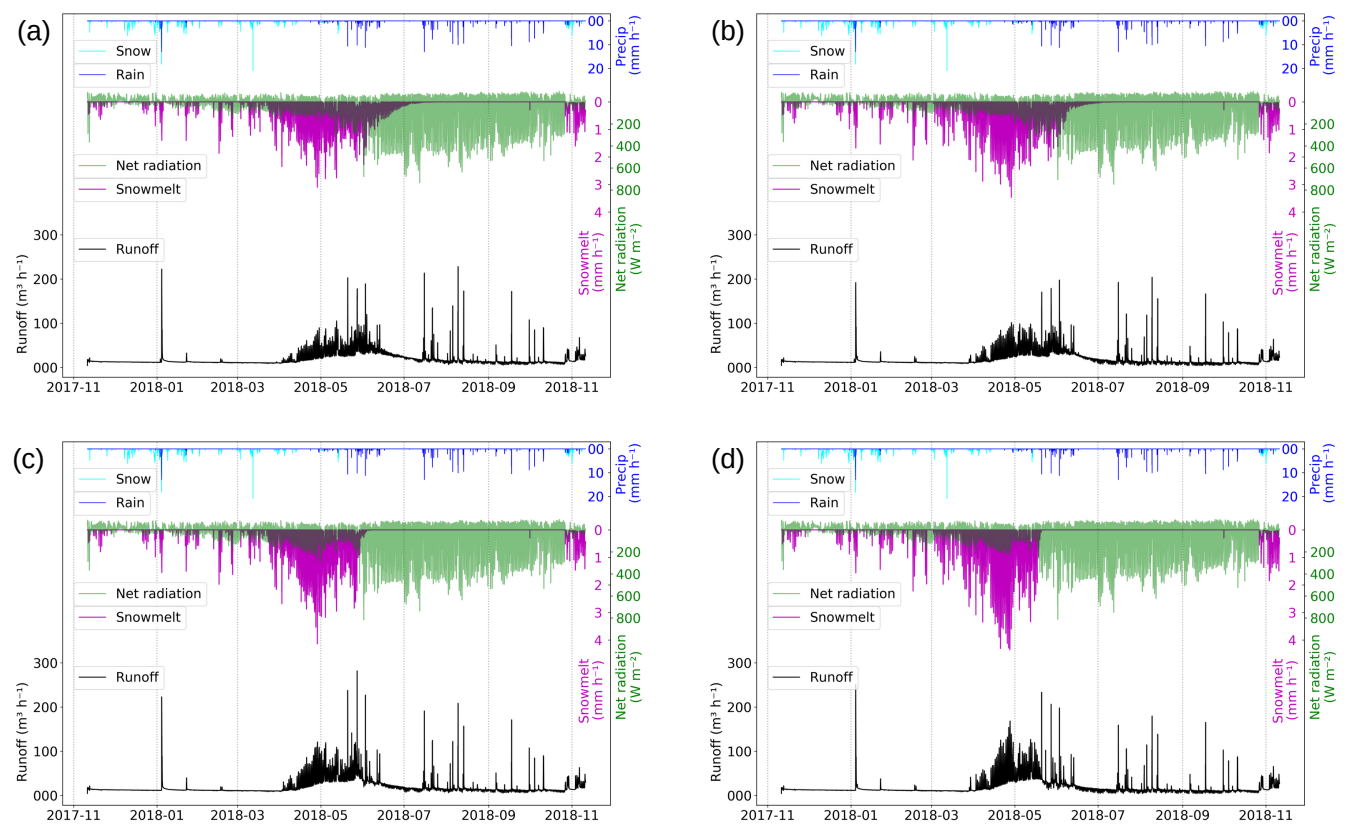

Figure 6. Same figure as 5a for (a) all distributed run (2D-AD), (b) only precipitation distributed run (2D-PD), (c) only shortwave distributed run (2D-SD) and (d) only shortwave distributed run (2D-WD).

Looking at the surface fluxes on Fig. 6a, one can see that the simulation with all distributed forcing (2D-AD) have longer snowmelt period with a long steady decline during the streamflow recession till mid-July. Compared to the non-distributed forcing simulation 1D-PM, the distributed forcing is causing a smoother snowmelt dynamic which last till July and correspondingly impacts the net radiation recharge and streamflow discharge dynamic with significant differences for streamflow values during the core of the melting period up to 50

Looking at individually distributed simulation results, it seems that this smoothing effect is caused by both the precipitation and short wave radiation distribution (Fig. 6b, c). At the contrary only wind distributed (2D-WD) results seems very similar to the non-distributed results. One can even refer to (Fig 6d) for easier inter-comparison with (Fig. 5a). The melting period tail length seems to be controlled by the snow pack depth variability (Fig. 9a, b) and higher accumulated snow on some pixels. This is combined with solar radiation effects which also produces melting spatial variability on the catchment even if the snow precipitation is uniformly distributed (Fig 6c). Only wind distribution (2D-WD) simulation, showed the highest melting regimes from mid-March to mid-May when temperatures and incoming radiations are favourable for melting with daily melting peaks upper than 4mm h-1 (Fig. 6d). In detail, wind distribution increase melting rates which led to higher runoff (Fig. 8d) when compared to 1D-PM.

Streamflow differences between simulations basically follow the melting differences. The 20 day April rain-on-snow period is particularly marked on streamflow on Fig. $6 a$, b. It has to be reminded that there are differences in term of incoming solar radiation between simulations. Unsurprisingly 2D-WD and 2D-PD simulation show larger streamflow values compared to 2D- 
$\mathrm{AD}$ and 2D-SD simulations because for the two first, the catchment receives $38.7 \mathrm{~W} \mathrm{~m}-2$ less than for the 2 last. Concerning the summer period, it is difficult to see any differences on streamflow.

Figure 7 shows observed and simulated evapotranspiration time series over the two weeks summer window from 08/07 to 25/07 and scatterplots over the three vegetative months from early June to end of August. This is a snow-free period. For better comparison with observations we selected simulated pixels in an approximated footprint area based on a wind direction mask (Fig. 1) and averaged simulated values over the mask. The wind direction mask is prepared according to the prevailing wind directions towards the Flux' Alp station between 10 percentile $\left(122.39^{\circ}\right)$ and 90 percentile $\left(260.51^{\circ}\right)$ wind direction. Pixel simulation (Pix-PM) corresponds to the 1D vertical column run at Flux'Alp cell (without lateral flow).
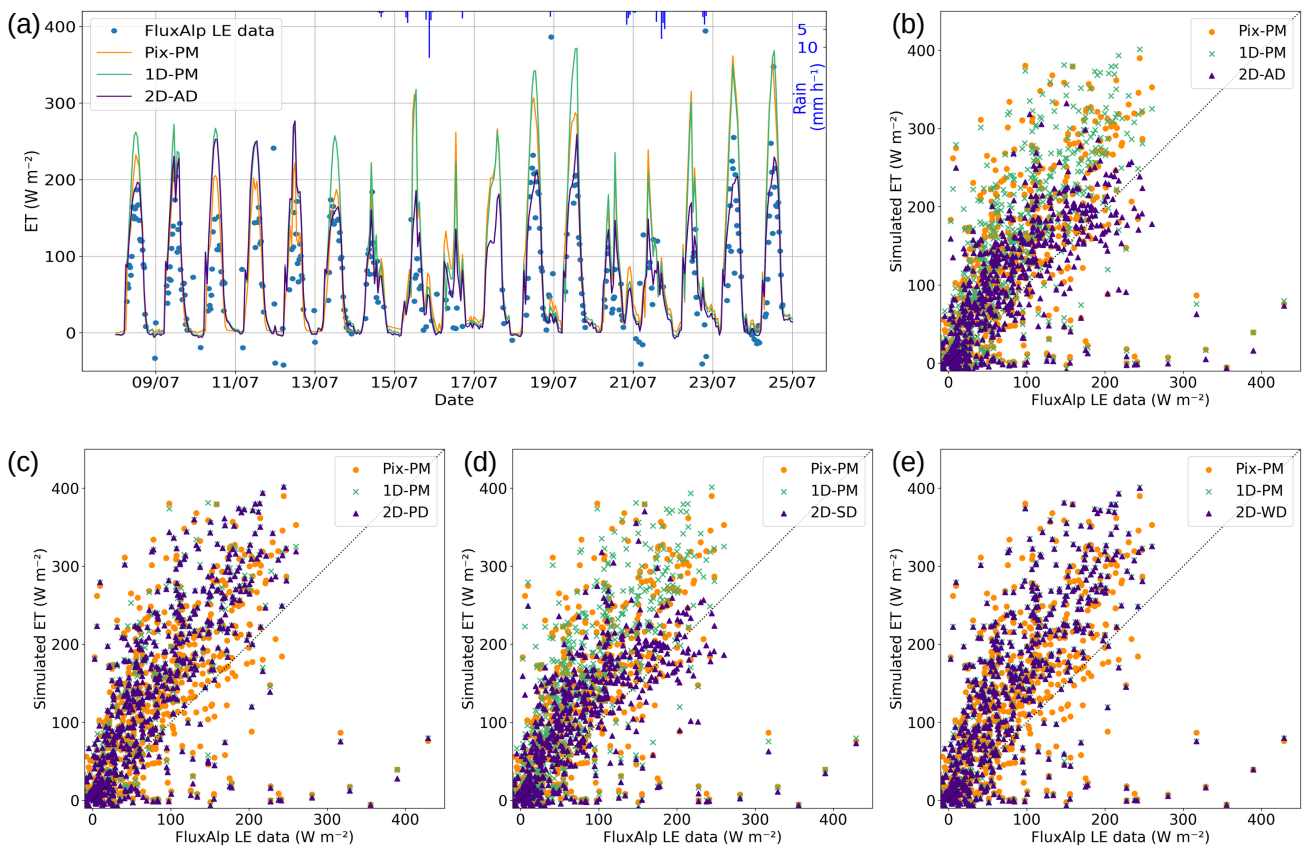

Figure 7. (a) Evapotranspiration simulation masked with wind direction mask for 17 days in summer for all distributed run (2D-AD). Scatter plot for the June-August 2018 period for (b) all distributed run (2D-AD), (c) only precipitation distributed run (2D-PD), (d) only shortwave distributed run (2D-SD) and (e) only wind distributed run (2D-WD).

The pixel run (saffron curve and saffron dots) clearly overestimated observed evapotranspiration as one can see on both the time series and the scatter plots. This is also the case for the Non-distributed simulation (green curve and green dots) and for 2D-PD and 2D-WD which have comparable evapotranspiration amplitude (Fig 7c, e). However, 2D-AD and 2D-SD have reduced simulated ET which better matches the observations (Fig 7d-b). The cause is that the average shortwave after the distribution is less than the shortwave without distribution (section 4) and the catchment is facing east which reduces direct incoming solar radiation from noon to sunset.

The evapotranspiration of both Pix-PM and 1D-PM over-estimate ET compared to observations. First the pixel run (PixPM) is supposed to simulate a catchment border (Flux'Alp location) with dryer soil/ground condition (top of a catena) and 


\begin{tabular}{|cccccc|}
\hline Simulations & Precipitation $(\mathrm{mm})$ & Runoff $(\mathrm{mm})$ & Runof coef. $(\mathrm{mm})$ & ET $(\mathrm{mm})$ & Stock $(\mathrm{mm})$ \\
\hline 1D-PM & 1443.72 & 1060.74 & 0.73 & 372.94 & 0.15 \\
\hline 1D-AM & 1443.72 & 1124.38 & 0.78 & 262.77 & 34.61 \\
\hline 2D-AD & 1443.72 & 1097.25 & 0.77 & 266.26 & 32.34 \\
\hline 2D-PD & 1443.72 & 1047.83 & 0.73 & 361.37 & -4.30 \\
\hline 2D-SD & 1443.72 & 1098.89 & 0.76 & 269.09 & 33.70 \\
\hline 2D-WD & 1443.72 & 1047.94 & 0.73 & 371.82 & 15.50 \\
\hline
\end{tabular}

Table 1. Annual water budget terms in the watershed for different chosen runs.

the ET observations are supposed to average both the wet zone close to the river and dryer zones. To the first order, it is not the case in our pixel and 1D-PM simulations. Shortwave distribution (Fig. 7d) seems to have the most important impact in our measurement area. The corresponding reduced ET in 2D-SD (and 2D-AD), averaged on the footprint area, also corresponds much better to the Eddy-Covariance observations.

\subsection{Water budget}

Annual water budgets in (Table 1) shows that the main impact of forcing distribution is caused by the shortwave distribution and subsequent ET calculation. This increases the runoff coefficient from 0.73 to 0.77 . One can note the water storage change over the year. As we started from the same initial conditions for all simulations, it reaches more than $30 \mathrm{~mm}$ when $\mathrm{SW}$ is reduced (1D-AM, 2D-AD and 2D-SD) and $15.5 \mathrm{~mm}$ for 2D-WD simulation. It remains smaller than the ET difference and it minimizes runoff coefficient hence not change our conclusions.

Figure 8 shows monthly water budgets for 2D-AD and individually distributed simulations. Snow precipitation from November to March doesn't infiltrates much to fill up the subsurface stock (dotted line). January rain on snow events slightly reduces the subsurface drainage. Very similar runoff values are observed whatever the forcing. In contrast, from mid-March to June the subsurface stock is replenished by melting (Fig. 5a, Fig. 6) and runoff increased. The 2D-WD forcing produced the largest values of recharge $(430 \mathrm{~mm})$ and the 2D-SD the largest values of streamflow. From May to October, streamflow at the outlet and ET drawdown subsurface stock. Higher SW radiations (2D-PD and 2D-WD) led to longer ET periods. One can finally note that reduced ET because of vegetation senescence in November leads to increased subsurface stock.

\subsection{Snow dynamics}

Figure 9 shows the temporal dynamic of the snow mantle and the impact in terms of albedo. Snow depth plots for Pix-PM run (purple line) and 1D-PM run (red line) are superimposed. The 1D-PM run shows little variability in snow depth (red shading). These two run follow a dynamic consistent with the observations (black line) with an overestimation along the accumulation period probably because of the rough snow/rain partition temperature threshold and the inability of the snow scheme to account 
(a)

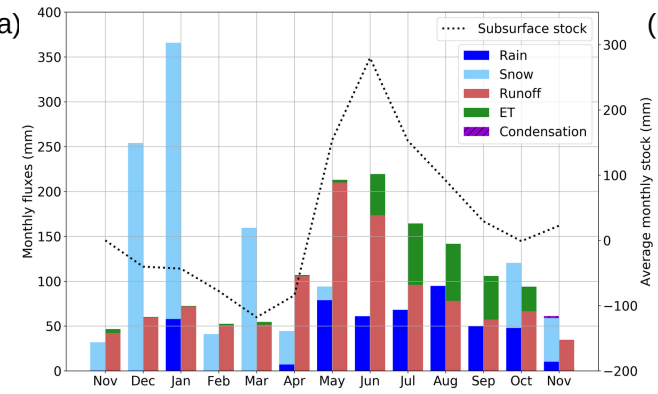

(c)

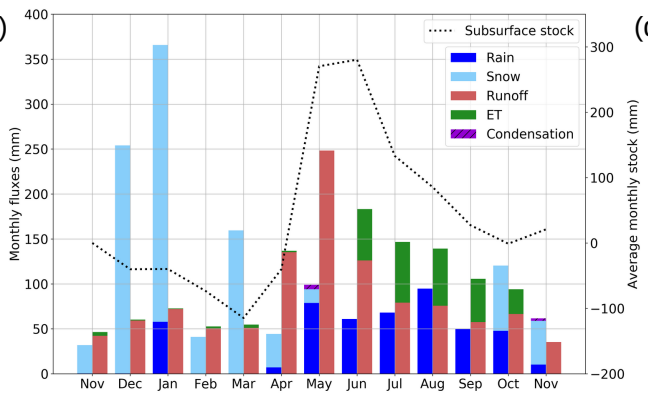

(b)

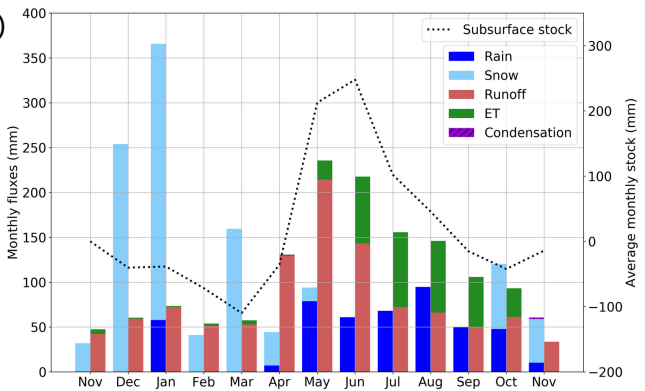

(d)

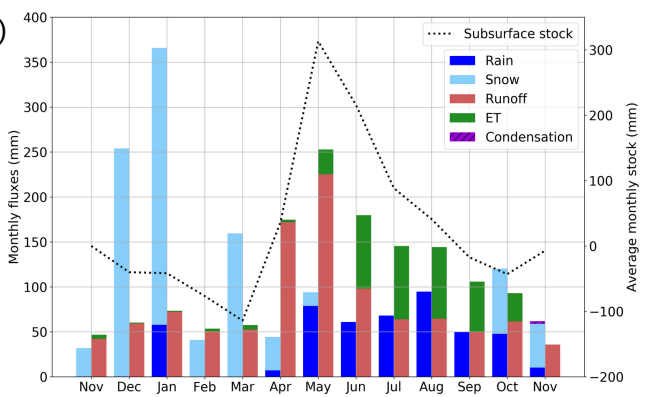

Figure 8. Same figure as $5 \mathrm{~b}$ for (a) all distributed run (2D-AD), (b) only precipitation distributed run (2D-PD), (c) only shortwave distributed run (2D-SD) and (d) only wind distributed run (2D-WD).

for compaction. The snowmelt dynamic is particularly well simulated, especially along the dry period at the end of April. In early May one can note some discrepancies again probably because of our limited ability to separate rain and snow in the precipitation forcing, close to the phase change temperature range. This can be seen on the pixel simulated Albedo which return to its snow value at the end of the melting season $(0.8)$, which is not the case on the observations. Concerning simulated albedo, it globally follows the observations, however it is clear that the snow age parameterisation in the model is not adequate enough to simulate the albedo where observation does not show albedo decrease during dry periods.

Blue line on figure 9a shows the average snow depth for the all-distributed simulation (2D-AD) and the sky blue shading in the same figure shows spatial variability between min and max snow depth over all pixels. For this simulation patchiness starts early in May and some pixels snow coverage last up more than one month later than the 1D-PM simulation. Depth variability is mainly increasing during accumulation events and is slightly reduced during melting. This effect can also be seen on the 2D-PD simulation but not on the other ones (Fig. 9b). As 2D-AD and 2D-PD simulations were prescribed the same input radiation and temperature, this means this effect (the deeper the snow, the faster the melting) is intrinsic to the snow scheme. At the contrary, 2D-SD simulation shows a slight increase of depth variability during the melting period.

It can be observed in (Fig. 9b) that none of the individually distributed simulations have longer snow coverage compared to the all distributed run (Fig. 9a). It indicates that snow variability during accumulation events is not enough to capture the actual behaviour of snow dynamics. The combination of both forcing results in longer snow periods with more patchiness accounting for precipitation spatial variability during accumulation events and shortwave spatial distribution dominance for differential 
(a)

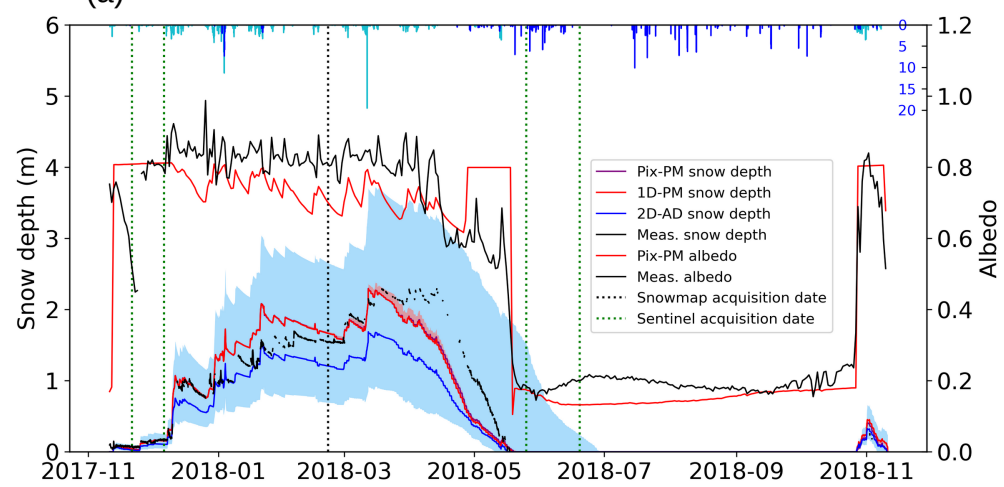

(b)

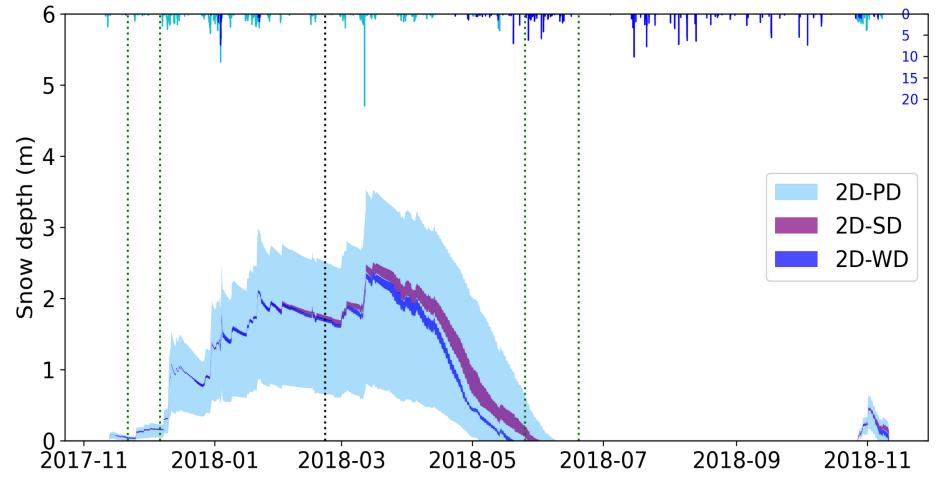

Figure 9. (a) Snow depth (left axis) for different simulations compared with observations (black line). Colour lines are the average depth over the catchment and shadings the spatial variability. Right axis: observed (black line) and 1D-PM Simulated albedo (red line). Averaged precipitations (right blue axis) are plotted at the top of the graph. (b) same as (a) but for the only precipitation (2D-PD), only shortwave (2D-SD) and only wind (2D-WD) distributed run.

melting. The 2D-WD simulation does not show much impact on the snow depth variability which is very similar to the 1D-PM simulation at the end of the snow period (Fig. 9b). However along spring (mid-March to end of April) it produced the same snow depth spatial variability as 2D-SD and higher snowmelt regimes (Fig. 9b and 6d). Wind distribution is then impacting snow patchiness through wind transport (accounted for in the snow distribution algorithm) and is increasing melting through the energy budget.

Spatial distribution of snow coverage during the melting period is shown on figure 10 for all simulations. For comparison and validation, we used four cloud-free 'Sentinel-2' images (Table 2). In the model, the snow pixels were selected for snow depth threshold over $1 \mathrm{~cm}$. The Sentinel snow pixels were selected with normalised snow difference index (NDSI) $>0.4$ (Riggs et al., 1994).

The 21st of November, first snow events were followed by a partial melting over the catchment (1st sentinel image). Our 2D-AD and 2D-PD simulations show a partial success in representing this feature, but the simulated melting was overall too 

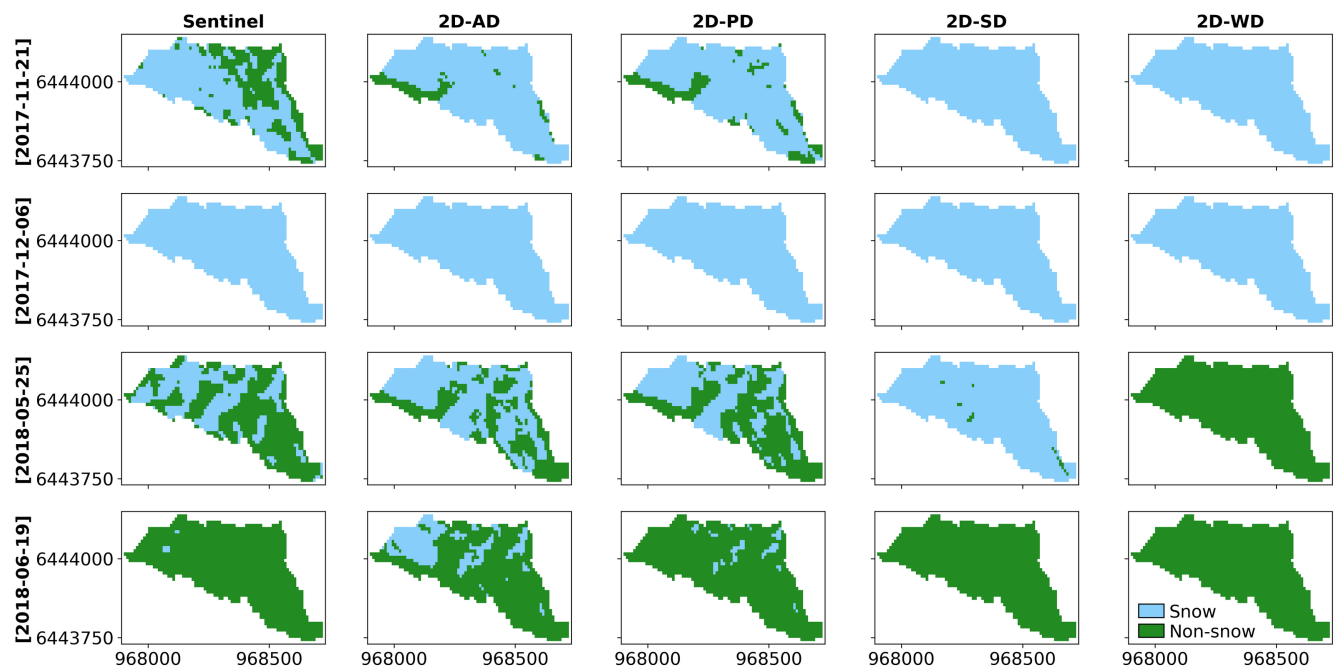

Figure 10. Snow map for different simulations compared with the Sentinel-2 images for 4 cloud free images: snow pixels (light skyblue) and non-snow pixel (green).

\begin{tabular}{|cccccc|}
\hline & Satellite platform & Date of acquisition & Resolution $(\mathrm{m})$ & Cloud cover $(\%)$ & Cloud cover over watershed $(\%)$ \\
\hline 1 & Sentinel 2B & $2017-11-21$ & 10 & 1.2 & None \\
\hline 2 & Sentinel 2A & $2017-12-06$ & 10 & 3.3 & None \\
\hline 3 & Sentinel 2A & $2018-05-25$ & 10 & 12.8 & None \\
\hline 4 & Sentinel 2B & $2018-06-19$ & 10 & 2.1 & None \\
\hline
\end{tabular}

Table 2. Details of Sentinel-2 image acquisition from USGS.

small. It is interesting to see that, apart from the upper part of the catchment where snow distribution is not well controlled, the first pixels that get out of snow are the eastern edge of the catchment, a central area aligned with the river, and the outlet area. The 2D-AD simulation has less green pixels because reduced incoming radiation caused by reduced solar angle, reduced the melting. On 6th of December, the catchment is completely covered by snow for all simulation. This date still also corresponds to early season snow events. The 2D-AD and 2D-PD simulations are able to represent the snow dynamic even for very low snow depth at the beginning of the season. This means in particular that 1) our spinup process has initiated well the ground temperature profile and distribution and 2) our distribution algorithm is well adapted, especially for snow deposition. The 25th of May is located when snow partially cover the catchment during the melting period. Again 2D-PD simulation represent very well the snow pixels to non-snow pixels ratio and the snow distribution. One can see on both Sentinel image and 2D-PD simulation some SW-NE alignment slightly present on the snow distribution coefficient map (green/blue pixels on Fig. 1c), the timing of disappearance is remarkably well simulated for this simulation. The $2 \mathrm{D}-\mathrm{AD}$ is not as good because of more snow coverage than the sentinel image. Because of a reduced melting when taking into account the solar incidence, this run is 
slightly late at melting. However, this does not mean that 2D-AD simulation is worse than the 2D-PD one. We have already shown the capability of 2D-AD run in capturing the better ET dynamics as compared to 2D-PD (Fig. 7b, 7d). Looking at the laser scan date, it shows, a $+0.5 \mathrm{~m}$ difference between the snow accumulation and the laser scan. This means that the snow distribution coefficient map we used probably overestimated the distribution range. One could play with precipitation correction coefficients or distribution coefficient map to have a better run but it would have hidden the snow scheme default and it was not our goal in this study to calibrate the model.

Over all, simulation results show good agreement with observations in term of snow dynamic and evapotranspiration. The presented simulations disentangle the combined effects of snow distribution and solar radiation which make us able to simulate realistic patchy snow coverage at $10 \mathrm{~m}$ resolution which is a commonly observed phenomenon over mid altitude mountainous catchment (Revuelto et al., 2017). These processes impact snow-hydrological budget over a sensitive sub-alpine catchment. Fan et al. (2019) highlighted the inclusion of two main processes to account in the ESMs which includes the slope/aspect effect and soil depth. In this study we precise how slope/aspect impact spatial variability in meteorological forcing from the surface to subsurface processes and how it can be included successfully in critical zone hydrological models.

\section{Conclusions}

Earth system models are gaining ample highlight in socio-economic impact studies. They include more and more processes including the complete continental water cycle but still face difficulty to parameterize small scale sub-mesh processes, which are crucial in mountain landscapes both for surface hydrology and feedbacks on climate. In this study we modelled the spatial variability of the snow coverage over a small mid-altitude catchment and its impact on the hydrological budget using the 3D critical-zone model ParFlow-CLM at $10 \mathrm{~m}$ resolution. For this purpose, we prepared distributed forcing for precipitation (that include snow transport), incoming solar radiation (that include differential snow melting) and wind speed to force the model. We showed the snow lasts longer for more than a month in our modeling setup when distributing all forcings compared to non-distributed forcing. These longer snow-stays lead to a significant impact on the hydrological cycle from increased water storage to evapotranspiration regime. We showed that the precipitation distribution had the largest impacts on hydrological behaviour because it favours the appearance of no-snow patches in the melting season. Shortwave distribution had a smaller effect at creating no snow patches in our simulation but enhanced the differential melting when combined with precipitation distribution. Our wind distribution simulation also induced melting spatial variability in the core of the melting period but reduces at the end of the melting period, as only taken into account for evapotranspiration processes. However, wind has a major role on snow re-distribution. This was well accounted for in our precipitation distribution algorithm using a laser scan of the snow mantle during the core accumulation period which registered snow variability aligned with the prevailing wind direction. Furthermore, accounting for distributed solar incidence reduced incoming radiation in our catchment subsequently reduced the evapotranspiration. This led to higher runoff coefficients at catchment scale. In conclusion, this study shows the relative importance of small-scale processes in earth system models when run at hyper-resolution. The terrain substantially controls the hydrological behaviour in the mid-elevation alpine catchment for runoff generation but also for evapotranspiration, 
https://doi.org/10.5194/hess-2021-639

Preprint. Discussion started: 10 January 2022

(c) Author(s) 2022. CC BY 4.0 License.

snow dynamic which has to be accounted accordingly for hydrological processes. It will help to minimise the erratum in water resource management.

Code and data availability. The script to run the model and supporting forcing data will be made available through a public git repository.

Author contributions. A. Gupta, A. Reverdy, J-M. Cohard, designed the experiments and prepared all the necessary inputs to run the model, and A. Gupta performed the simulations. R. Maxwell and B. Hector developed the model Parflow/CLM Model version for this study, D. Voisin processed required meteorological data, M. Descloitres and J-P. Vandervaere provided soil and aquifer properties, C. Coulaud, L. Liger and R. Biron manage Eddy Covariance micro-meteorological station and all field works at Lautaret Pass, J-G. Valay and D. Voisin brings the necessary support to make this study possible. A. Gupta and J-M. Cohard prepared the manuscript with contributions from all co-authors.

Competing interests. The authors declare that they have no conflict of interest.

Acknowledgements. This research was conducted within the Long-Term Socio-Ecological Research (LTSER) platform Lautaret-Oisans, a site of the European Research Infrastructure eLTER. It received funding from the Lautaret Garden (Univ. Grenoble Alpes, CNRS, LAUTARET, 38000 Grenoble, France), a member of the Zone Atelier Alpes and the eLTER network and from ANR project ANR-15IDEX-02. 


\section{References}

Aguayo, M. A., Flores, A. N., McNamara, J. P., Marshall, H.-P., and Mead, J.: Examining cross-scale influences of forcing resolutions in a hillslope-resolving, integrated hydrologic model, Hydrol. Earth Syst. Sci. Discuss., 1-28, https://doi.org/10.5194/hess-2020-451, 2020.

Ashby, S. F. and Falgout, R. D.: A parallel multigrid preconditioned conjugate gradient algorithm for groundwater flow simulations, Nucl. Sci. Eng., 124, 145-159, 1996.

Baba, M. W., Gascoin, S., Kinnard, C., Marchane, A., and Hanich, L.: Effect of Digital Elevation Model Resolution on the Simulation of the Snow Cover Evolution in the High Atlas, Water Resour. Res., 55, 5360-5378, https://doi.org/10.1029/2018WR023789, 2019.

Bertoldi, G., Della Chiesa, S., Notarnicola, C., Pasolli, L., Niedrist, G., and Tappeiner, U.: Estimation of soil moisture patterns in mountain grasslands by means of SAR RADARSAT2 images andhydrological modeling, J. Hydrol., 516, 245-257, https://doi.org/10.1016/j.jhydrol.2014.02.018, 2014.

Blöschl, G., Bierkens, M. F. P., Chambel, A., Cudennec, C., Destouni, G., Fiori, A., Kirchner, J. W., McDonnell, J. J., Savenije, H. H. G., Sivapalan, M., Stumpp, C., Toth, E., Volpi, E., Carr, G., Lupton, C., Salinas, J., Széles, B., Viglione, A., Aksoy, H., Allen, S. T., Amin, A., Andréassian, V., Arheimer, B., Aryal, S. K., Baker, V., Bardsley, E., Barendrecht, M. H., Bartosova, A., Batelaan, O., Berghuijs, W. R., Beven, K., Blume, T., Bogaard, T., Amorim, P. B. de, Böttcher, M. E., Boulet, G., Breinl, K., Brilly, M., Brocca, L., Buytaert, W., Castellarin, A., Castelletti, A., Chen, X., Chen, Y., Chen, Y., Chifflard, P., Claps, P., Clark, M. P., Collins, A. L., Croke, B., Dathe, A., David, P. C., Barros, F. P. J. de, Rooij, G. de, Baldassarre, G. D., Driscoll, J. M., Duethmann, D., Dwivedi, R., Eris, E., Farmer, W. H., Feiccabrino, J., Ferguson, G., Ferrari, E., Ferraris, S., Fersch, B., Finger, D., Foglia, L., Fowler, K., Gartsman, B., Gascoin, S., Gaume, E., Gelfan, A., Geris, J., Gharari, S., Gleeson, T., Glendell, M., Bevacqua, A. G., González-Dugo, M. P., Grimaldi, S., Gupta, A. B., Guse, B., Han, D., Hannah, D., Harpold, A., Haun, S., Heal, K., Helfricht, K., Herrnegger, M., Hipsey, M., Hlaváčiková, H., Hohmann, C., Holko, L., Hopkinson, C., Hrachowitz, M., Illangasekare, T. H., Inam, A., Innocente, C., Istanbulluoglu, E., Jarihani, B., et al.: Twenty-three unsolved problems in hydrology (UPH) - a community perspective, Hydrol. Sci. J., 64, 1141-1158, https://doi.org/10.1080/02626667.2019.1620507, 2019.

Brutsaert, W.: The surface roughness parameterization, in: Evaporation into the Atmosphere, Springer, 113-127, 1982.

Clark, M. P., Fan, Y., Lawrence, D. M., Adam, J. C., Bolster, D., Gochis, D. J., Hooper, R. P., Kumar, M., Leung, L. R., Mackay, D. S., Maxwell, R. M., Shen, C., Swenson, S. C., and Zeng, X.: Improving the representation of hydrologic processes in Earth System Models, Water Resour. Res., 51, 5929-5956, https://doi.org/10.1002/2015WR017096, 2015.

Condon, L. E. and Maxwell, R. M.: Modified priority flood and global slope enforcement algorithm for topographic processing in physically based hydrologic modeling applications, Comput. Geosci., 126, 73-83, https://doi.org/10.1016/j.cageo.2019.01.020, 2019.

Costa, D., Shook, K., Spence, C., Elliott, J., Baulch, H., Wilson, H., and Pomeroy, J. W.: Predicting Variable Contributing Areas, Hydrological Connectivity, and Solute Transport Pathways for a Canadian Prairie Basin, Water Resour. Res., 56, e2020WR027984, https://doi.org/10.1029/2020WR027984, 2020.

Dai, Y., Zeng, X., Dickinson, R. E., Baker, I., Bonan, G. B., Bosilovich, M. G., Denning, A. S., Dirmeyer, P. A., Houser, P. R., Niu, G., Oleson, K. W., Schlosser, C. A., and Yang, Z.-L.: The Common Land Model, Bull. Am. Meteorol. Soc., 84, 1013-1024, https://doi.org/10.1175/BAMS-84-8-1013, 2003.

Dunne, T.: Relation of field studies and modeling in the prediction of storm runoff, J. Hydrol., 65, 25-48, https://doi.org/10.1016/00221694(83)90209-3, 1983.

470 Fan, Y., Clark, M., Lawrence, D. M., Swenson, S., Band, L. E., Brantley, S. L., Brooks, P. D., Dietrich, W. E., Flores, A., Grant, G., Kirchner, J. W., Mackay, D. S., McDonnell, J. J., Milly, P. C. D., Sullivan, P. L., Tague, C., Ajami, H., Chaney, N., Hartmann, A., Hazenberg, P., 
https://doi.org/10.5194/hess-2021-639

Hydrology and

Preprint. Discussion started: 10 January 2022

(C) Author(s) 2022. CC BY 4.0 License.

McNamara, J., Pelletier, J., Perket, J., Rouholahnejad-Freund, E., Wagener, T., Zeng, X., Beighley, E., Buzan, J., Huang, M., Livneh, B., Mohanty, B. P., Nijssen, B., Safeeq, M., Shen, C., Verseveld, W. van, Volk, J., and Yamazaki, D.: Hillslope Hydrology in Global Change Research and Earth System Modeling, Water Resour. Res., 55, 1737-1772, https://doi.org/10.1029/2018WR023903, 2019.

Fang, X. and Pomeroy, J. W.: Diagnosis of future changes in hydrology for a Canadian Rockies headwater basin, Hydrol. Earth Syst. Sci., 24, 2731-2754, https://doi.org/10.5194/hess-24-2731-2020, 2020.

Günther, D., Marke, T., Essery, R., and Strasser, U.: Uncertainties in Snowpack Simulations-Assessing the Impact of Model Structure, Parameter Choice, and Forcing Data Error on Point-Scale Energy Balance Snow Model Performance, Water Resour. Res., 55, 2779-2800, https://doi.org/10.1029/2018WR023403, 2019.

Hellström, M., Vermeulen, A., Mirzov, O., Sabbatini, S., Vitale, D., Papale, D., Tarniewicz, J., Hazan, L., Rivier, L., and Jones, S. D.: Near Real Time Data Processing In ICOS RI, in: 2nd international workshop on interoperable infrastructures for interdisciplinary big data sciences (it4ris 16) in the context of ieee real-time system symposium (rtss), 2016.

Horton, R. E.: The Rôle of infiltration in the hydrologic cycle, Eos Trans. Am. Geophys. Union, 14, 446-460, https://doi.org/10.1029/TR014i001p00446, 1933.

Van den Hurk, B., Best, M., Dirmeyer, P., Pitman, A., Polcher, J., and Santanello, J.: Acceleration of land surface model development over a decade of GLASS, Bull. Am. Meteorol. Soc., 92, 1593-1600, 2011.

Hurrell, J. W., Holland, M. M., Gent, P. R., Ghan, S., Kay, J. E., Kushner, P. J., Lamarque, J.-F., Large, W. G., Lawrence, D., Lindsay, K., Lipscomb, W. H., Long, M. C., Mahowald, N., Marsh, D. R., Neale, R. B., Rasch, P., Vavrus, S., Vertenstein, M., Bader, D., Collins, W. D., Hack, J. J., Kiehl, J., and Marshall, S.: The Community Earth System Model: A Framework for Collaborative Research, Bull. Am. Meteorol. Soc., 94, 1339-1360, https://doi.org/10.1175/BAMS-D-12-00121.1, 2013.

Jefferson, J. L. and Maxwell, R. M.: Evaluation of simple to complex parameterizations of bare ground evaporation, J. Adv. Model. Earth Syst., 7, 1075-1092, https://doi.org/10.1002/2014MS000398, 2015.

Jones, J. E. and Woodward, C. S.: Newton-Krylov-multigrid solvers for large-scale, highly heterogeneous, variably saturated flow problems, Adv. Water Resour., 24, 763-774, 2001.

Klok, E. J., Jasper, K., Roelofsma, K. P., Gurtz, J., and Badoux, A.: Distributed hydrological modelling of a heavily glaciated Alpine river basin, Hydrol. Sci. J., 46, 553-570, 2001.

Kollet, S. J. and Maxwell, R. M.: Integrated surface-groundwater flow modeling: A free-surface overland flow boundary condition in a parallel groundwater flow model, Adv. Water Resour., 29, 945-958, https://doi.org/10.1016/j.advwatres.2005.08.006, 2006.

Kollet, S. J. and Maxwell, R. M.: Capturing the influence of groundwater dynamics on land surface processes using an integrated, distributed watershed model, Water Resour. Res., 44, https://doi.org/10.1029/2007WR006004, 2008.

Kuffour, B. N. O., Engdahl, N. B., Woodward, C. S., Condon, L. E., Kollet, S., and Maxwell, R. M.: Simulating coupled surface-subsurface flows with ParFlow v3.5.0: capabilities, applications, and ongoing development of an open-source, massively parallel, integrated hydrologic model, Geosci. Model Dev., 13, 1373-1397, https://doi.org/10.5194/gmd-13-1373-2020, 2020.

Liston, G. E. and Elder, K.: A Meteorological Distribution System for High-Resolution Terrestrial Modeling (MicroMet), J. Hydrometeorol., 7, 217-234, https://doi.org/10.1175/JHM486.1, 2006.

Liston, G. E., Perham, C. J., Shideler, R. T., and Cheuvront, A. N.: Modeling snowdrift habitat for polar bear dens, Ecol. Model., 320, 114-134, https://doi.org/10.1016/j.ecolmodel.2015.09.010, 2016.

Loritz, R., Hrachowitz, M., Neuper, M., and Zehe, E.: The role and value of distributed precipitation data in hydrological models, Hydrol. Earth Syst. Sci., 25, 147-167, https://doi.org/10.5194/hess-25-147-2021, 2021. 
https://doi.org/10.5194/hess-2021-639

Hydrology and

Preprint. Discussion started: 10 January 2022

(c) Author(s) 2022. CC BY 4.0 License.

510 Marsh, C. B., Pomeroy, J. W., Spiteri, R. J., and Wheater, H. S.: A Finite Volume Blowing Snow Model for Use With Variable Resolution Meshes, Water Resour. Res., 56, e2019WR025307, https://doi.org/10.1029/2019WR025307, 2020.

Maxwell, R. M.: A terrain-following grid transform and preconditioner for parallel, large-scale, integrated hydrologic modeling, Adv. Water Resour., 53, 109-117, 2013.

Maxwell, R. M. and Miller, N. L.: Development of a coupled land surface and groundwater model, J. Hydrometeorol., 6, 233-247, 2005.

515 Meerveld, H. J. T., James, A. L., McDonnell, J. J., and Peters, N. E.: A reference data set of hillslope rainfall-runoff response, Panola Mountain Research Watershed, United States, Water Resour. Res., 44, https://doi.org/10.1029/2007WR006299, 2008.

Nijssen, B. and Lettenmaier, D. P.: A simplified approach for predicting shortwave radiation transfer through boreal forest canopies, J. Geophys. Res. Atmospheres, 104, 27859-27868, https://doi.org/10.1029/1999JD900377, 1999.

Oleson, K. W., Dai, Y., Bonan, G., Bosilovich, M., Dickinson, R., Dirmeyer, P., Hoffman, F., Houser, P., Levis, S., and Niu, G.-Y.: Technical description of the community land model (CLM), Tech Note NCARTN-461 STR, 2004.

Pomeroy, J. W. and Li, L.: Prairie and arctic areal snow cover mass balance using a blowing snow model, J. Geophys. Res. Atmospheres, 105, 26619-26634, https://doi.org/10.1029/2000JD900149, 2000.

Pomeroy, J. W., Toth, B., Granger, R. J., Hedstrom, N. R., and Essery, R. L. H.: Variation in Surface Energetics during Snowmelt in a Subarctic Mountain Catchment, J. Hydrometeorol., 4, 702-719, https://doi.org/10.1175/1525-7541(2003)004<0702:VISEDS>2.0.CO;2, 2003.

Pomeroy, J. W., Gray, D. M., Brown, T., Hedstrom, N. R., Quinton, W. L., Granger, R. J., and Carey, S. K.: The cold regions hydrological model: a platform for basing process representation and model structure on physical evidence, Hydrol. Process., 21, 2650-2667, https://doi.org/10.1002/hyp.6787, 2007.

Revuelto, J., Azorin-Molina, C., Alonso-González, E., Sanmiguel-Vallelado, A., Navarro-Serrano, F., Rico, I., and López-Moreno, J. I.: Meteorological and snow distribution data in the Izas Experimental Catchment (Spanish Pyrenees) from 2011 to 2017 , Earth Syst. Sci. Data, 9, 993-1005, https://doi.org/10.5194/essd-9-993-2017, 2017.

Revuelto, J., Billecocq, P., Tuzet, F., Cluzet, B., Lamare, M., Larue, F., and Dumont, M.: Random forests as a tool to understand the snow depth distribution and its evolution in mountain areas, Hydrol. Process., 34, 5384-5401, https://doi.org/10.1002/hyp.13951, 2020.

Reynolds, W. D. and Elrick, D. E.: Determination of hydraulic conductivity using a tension infiltrometer, Soil Sci. Soc. Am. J., 55, 633-639, 1991.

Riggs, G. A., Hall, D. K., and Salomonson, V. V.: A snow index for the Landsat Thematic Mapper and Moderate Resolution Imaging Spectroradiometer, in: Proceedings of IGARSS '94 - 1994 IEEE International Geoscience and Remote Sensing Symposium, Proceedings of IGARSS '94 - 1994 IEEE International Geoscience and Remote Sensing Symposium, 1942-1944 vol.4, https://doi.org/10.1109/IGARSS.1994.399618, 1994.

540 Sampaio, R. J., Rodriguez, D. A., Von Randow, C., da Silva, F. P., de Araújo, A. A. M., and Filho, O. C. R.: Sensible heat flux assessment in a complex coastal-mountain urban area in the metropolitan area of Rio de Janeiro, Brazil, Meteorol. Atmospheric Phys., https://doi.org/10.1007/s00703-021-00812-2, 2021.

Song, J., Miller, G. R., Cahill, A. T., Aparecido, L. M. T., and Moore, G. W.: Modeling land surface processes over a mountainous rainforest in Costa Rica using CLM4.5 and CLM5, Geosci. Model Dev., 13, 5147-5173, https://doi.org/10.5194/gmd-13-5147-2020, 2020.

545 Sun, N., Wigmosta, M., Zhou, T., Lundquist, J., Dickerson-Lange, S., and Cristea, N.: Evaluating the functionality and streamflow impacts of explicitly modelling forest-snow interactions and canopy gaps in a distributed hydrologic model, Hydrol. Process., 32, 2128-2140, https://doi.org/10.1002/hyp.13150, 2018. 
https://doi.org/10.5194/hess-2021-639

Preprint. Discussion started: 10 January 2022

(c) Author(s) 2022. CC BY 4.0 License.

Tran, H., Zhang, J., Cohard, J.-M., Condon, L. E., and Maxwell, R. M.: Simulating Groundwater-Streamflow Connections in the Upper Colorado River Basin, Groundwater, 58, 392-405, https://doi.org/10.1111/gwat.13000, 2020.

550 Van Genuchten, M. T.: A closed-form equation for predicting the hydraulic conductivity of unsaturated soils, Soil Sci. Soc. Am. J., 44, 892-898, 1980.

Vandervaere, J.-P., Vauclin, M., and Elrick, D. E.: Transient flow from tension infiltrometers I. The two-parameter equation, Soil Sci. Soc. Am. J., 64, 1263-1272, 2000a.

Vandervaere, J.-P., Vauclin, M., and Elrick, D. E.: Transient flow from tension infiltrometers II. Four methods to determine sorptivity and conductivity, Soil Sci. Soc. Am. J., 64, 1272-1284, 2000b.

Vionnet, V., Brun, E., Morin, S., Boone, A., Faroux, S., Le Moigne, P., Martin, E., and Willemet, J.-M.: The detailed snowpack scheme Crocus and its implementation in SURFEX v7.2, Geosci. Model Dev., 5, 773-791, https://doi.org/10.5194/gmd-5-773-2012, 2012. 